\title{
Effects of different ingredients on antioxidant and oxidant status of brewed roasted coffee
}

\section{Yasemin ERTAŞ ÖZTÜRK' ${ }^{1}$, Duygu AĞAGÜNDÜZ²}

Cite this article as:

Ertaş Öztürk, Y., Ağagündüz, D. (2022). Effect of different ingredients on antioxidant and oxidant status of brewed roasted coffee. Food and Health, 8(1), 46-56. https://doi.org/10.3153/FH22005

${ }^{1}$ Ondokuz Mayıs University, Faculty of Health Sciences, Department of Nutrition and Dietetics, Samsun, Turkey

${ }^{2}$ Gazi University, Faculty of Health Sciences, Department of Nutrition and Dietetics, 06490 Emek, Ankara/Turkey

\section{ORCID IDs of the authors:}

Y.E.Ö. 0000-0002-8232-103X

D.A. 0000-0003-0010-0012

Submitted: 26.05 .2021

Revision requested: 10.08 .2021

Last revision received: 19.08 .2021

Accepted: 20.08.2021

Published online: 21.12 .2021

Correspondence:

Yasemin ERTAŞ ÖZTÜRK

E-mail:

yasemnertas@gmail.com

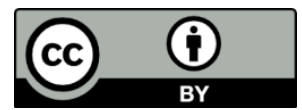

Available online at http://jfhs.scientificwebjournals.com

\begin{abstract}
It was aimed to evaluate the effects of different ingredients on total antioxidant status (TAS) and total oxidant status (TOS) of the brewed Brazil mild roasted coffee. Sugar, sucralose, butter, coconut-oil, animal and plant-based milk types were added and milk types\&sweeteners were combined separately. TAS and TOS were measured and oxidative stress indice (OSI) was calculated. TAS value of coffee with whole milk was the highest among all coffee types. TOS values of coffee with soy milk, with soy milk+sugar and soy milk+sucralose were lower than all other coffee types. When compared to OSI values, coffee with soy milk, with soy milk+sugar and soy milk+sucralose had the lowest OSI values among all coffee types. Moreover, addition of coconut-oil to coffee samples increased the TOS and OSI values of coffees. While the TOS and OSI of the sugar and sucralose addition were found higher in comparison to plain coffee; TOS and OSI of the sucralose addition was lower than those sugar combinations. In conclusion, the OSI of the coffee may change depending on the alterations of chemical structures and nutritional matrices by the added ingredients. The addition of soy milk or sucralose instead of sugar or whole cow milk instead of oil-based ingredients could be a promising strategy of reducing the oxidative capacity.
\end{abstract}

Keywords: Coffee, Milk, Sugar, Antioxidant, Oxidant 


\section{Introduction}

Coffee is one of the most popular beverages due to its aroma and potential health effects worldwide (Samoggia \& Riedel, 2019). Coffee compounds such as caffeine, chlorogenic acids, trigonelline, tryptophan alkaloids, diterpenes and other secondary metabolites are mainly responsible for its health benefits (Hu, Wang, Zhang, \& Qiu, 2019). To date, numerous studies have suggested that acute or habitual coffee consumption has been positively related with multiple health outcomes with its antioxidant, anti-inflammatory, anticancer and antidiabetic properties due to having such large bioactive chemical compounds (Poole et al., 2017).

Recently it has been hypothesized that coffee has a potential protective role of against oxidative stress mediators and associated diseases. Martini et al. (2016) reported that chronic consumption of coffee may increase some antioxidant biomarkers (glutathione levels) and reduce the levels of Deoxyribonucleic acid (DNA) damage (Daniela Martini et al., 2016). In another study, daily $400 \mathrm{~mL}$ coffee consumption for 8 weeks contained medium or high chlorogenic acids (CGAs) increased plasma antioxidant capacity without any detrimental effect on vascular function in healthy adults (Agudelo-Ochoa et al., 2016). On the other hand, receiving 3 or 5 cups of study coffee (freshly brewed Arabica coffee using a filter machine and drunk for 2 times/day as 1-2 cups or 2-3 cups) or control (water) for 8 weeks had no beneficial effect on either DNA or plasma lipid levels (Shaposhnikov et al., 2018). However, CGAs the main phenolic component of coffee is primarily responsible of health benefits and has been associated with reduction in oxidative stress and consequently inflammation and chronic disease prevention like cancer and diabetes. (Tajik, Tajik, Mack, \& Enck, 2017). Furthermore, other brewed coffee components such as some types of advanced glycation end products (AGEs) and/or colonic metabolites may responsible to inhibit plenty of diseases caused by oxidative damage as well (Gómez-Ruiz, Leake, \& Ames, 2007; Yanagimoto, Ochi, Lee, \& Shibamoto, 2004).

Roasting, manufacturing processes and preparation methods can alter antioxidant and phenolic substances of coffee (del Castillo, Ames, \& Gordon, 2002; Niseteo, Komes, BelščakCvitanović, Horžić, \& Budeč, 2012). Coffee can be consumed either plain or with desired flavoring ingredients such as sweeteners and/or milk (Samoggia \& Riedel, 2019). Nutritional value of the consumption trends of beverages are usually ignored in exploring the health effects of consumption habits. However, active substances of coffee can interact with additives and thus alterations might occur within its health benefits (Nakilcioğlu-Taş, 2018; Niseteo et al., 2012). Sugar addition to Turkish coffee while cooking is shown to reduce antioxidant capacity (Nakilcioğlu-Taş, 2018). In vitro gastrointestinal digestion model showed milk addition can alter the bioaccessibility of coffee phenolic compounds in addition with particular processing methods (Quan et al., 2020). Additionally, coffee added with milk that contains $7.1 \%$ of fat increased chlorogenic acid bioaccessibility upon in vitro digestion after using high-pressure homogenization (Alongi, Calligaris, \& Anese, 2019) suggesting higher milk fat enhances the bioaccessibility. On the other hand, milk additive $(25 \%)$ was found insignificant on coffee antioxidant status in another study (Dupas, Marsset-Baglieri, Ordonaud, Ducept, $\&$ Maillard, 2006). However, milk addition on coffee brews decreased antioxidant capacity and polyphenolic content of brews, which refers to potential interactions between polyphenols and milk nutrients (Niseteo et al., 2012). Furthermore, adding milk and sugar into decaffeinated coffee before a high glycaemic index meal may positively effect on postprandial glycaemic and insulinaemic responses in healthy adults (Tommy, Jennifer, Iris, Sit, \& Louie, 2020).

Impact of additive ingredients while consuming coffee and its health implications is poorly understood and results are conflicting. Especially, new trends like adding butter or coconut oil into brewed coffee and their effects on oxidation status have not been studied before. Since having important antioxidant properties, coffee might provide beneficial effects on oxidative stress markers as well and hence, human health (Martini et al., 2016). Therefore, we aimed to evaluate the effects of different ingredients on antioxidant and oxidant properties of brewed roasted coffee in the present study.

\section{Materials and Methods}

\section{Sample Selection and Brewing Conditions}

Roasted coffee beans (Brazil mild, roasted to 156-165 ${ }^{\circ} \mathrm{C}$ ) were supplied from a local coffee supplier. A coffee grinder (Russell Hobbs 23120-56, United Kingdom) were used to obtain grounded filter coffee. All samples were prepared with filter coffee machine in compliance with The Specialty Coffee Association's (2020) coffee cupping standards within 5 minutes. According to this standards brewing were done with the ratio of $8.25 \pm 0.25$ grams (whole bean) coffee to $150 \mathrm{~mL}$ water. Water temperature was $92.2-94.4{ }^{\circ} \mathrm{C}$ when poured on grounds. Then, tempered glass cups were used for cupping.

\section{Ingredients}

It was prepared plain (black) filter coffee as described above and added sugar $(5 \mathrm{~g})$, sucralose $(0.5 \mathrm{~g})$, butter $(5 \mathrm{~g})$, coconut oil (5 g), ultra high temperature (UHT) cow milk types (20\% $\mathrm{v} / \mathrm{v}, \sim 30 \mathrm{~mL}$ ); whole milk, light milk, lactose-free milk, and 
UHT coconut milk and soy milk at room temperature. Additionally, milk types and sweeteners were combined separately. Amount of milk was decided based on earlier literature (Al-Ghafari et al., 2017; Dupas et al., 2006); while the others were taken as one teaspoon (sucralose taken as equaling to same amount of sucrose). All ingredients were purchased from the local markets. Characteristics and nutrition facts of added ingredients to coffee were given in Table 1. The final temperatures of samples with ingredients were shown in Table 2 .

\section{Sample Analyses}

Brewed coffee was taken to tempered glass and added the ingredients. The final temperature of samples was measured. Then, coffee samples collected into micro tubes and analyzed immediately. All samples were analyzed in duplicate.

\section{Measurement of Temperature}

Water used for preparing coffee samples was heated using a heat adjustable kettle with glass chamber (Rossman ${ }^{\mathrm{TM}}$ ), and brewing temperatures were measured by a probe thermometer (Arcone TP101 ${ }^{\mathrm{TM}}$ ).

\section{Measurement of Water-Soluble Dry Matter Content}

A portable ATC Brix refractometer was used to measure of dry matter of brewed coffee samples. Briefly, the zero-calibration using distilled water was performed. Then, a few drops of the sample were placed on the measurement prism. The cover plate was closed for spreading the liquid across the entire surface of the prism and avoided to produce any air bubbles or dry spots. While holding the instrument under a light source, the Brix concentration ( ${ }^{\circ}$ ) was determined by the intersection of the boundary of the light and dark fields on the scale. After reading, the instrument was cleaned with distilled water immediately.

\section{Analysis of Total Antioxidant Status (TAS) and Total Oxidant Status (TOS)}

Total antioxidant status (TAS) and total oxidant status (TOS) of coffee samples were analyzed using commercially available kits (Relassay, Turkey) and Mindray BS300 Auto Biochemistry Analyzer ${ }^{\mathrm{TM}}$ following the kit protocol. Coffee samples were centrifuged (Selecta Centronic BLII) at $3000 \mathrm{rpm}$ for 2 minutes at $4^{\circ} \mathrm{C}$. For the measurement of TAS values the novel automated method were used based on the bleaching of characteristic color of a more stable 2,2 Azino-bis (3ethylbenzothiazoline-6-sulfonic acid (ABTS) radical cation by antioxidants. The precision value of assay was lower than $3 \%$. The change of absorbance at $660 \mathrm{~nm}$ is related with total antioxidant level of the sample. The results were expressed as mmol Trolox equivalent/L (Ozcan Erel, 2004).

For the measurement of TOS values, oxidants present in the sample oxidized the ferrous ion-o-dianisidine complex to ferric ion. The oxidation reaction was enhanced by glycerol molecules abundantly present in the reaction medium. The ferric ion produced a colored complex with xylenol orange in an acidic medium. The color intensity, measured by spectrophotometrically in $530 \mathrm{~nm}$, was related to the total amount of oxidant molecules present in the sample. The assay was calibrated with hydrogen peroxide and the results were expressed in terms of micro molar hydrogen peroxide equivalent per liter $\left(\mathrm{mol} \mathrm{H}_{2} \mathrm{O}_{2}\right.$ equivalent/L) (O. Erel, 2005).

\section{Calculation of Oxidative Stress Index (OSI)}

Oxidative stress index (OSI) were used as an indicator of oxidative stress (the ratio of TOS to TAS) calculated using the following formula (Yumru et al., 2009): OSI (arbitrary unit) $=\mathrm{TOS}\left(\mu \mathrm{mol} \mathrm{H}_{2} \mathrm{O}_{2}\right.$ equivalent/L) / TAS ( $\mu$ mol Trolox equivalent/L).

Table 1. Characteristics and nutrition facts of added ingredients

\begin{tabular}{lccccccc}
\hline \multirow{2}{*}{ Ingredients } & \multirow{2}{*}{ Brand } & \multicolumn{6}{c}{ Nutrition Facts (g/100 g) } \\
\cline { 3 - 8 } & & Carbohydrate & Sugars & Fat & SFA & Protein & Fiber \\
\hline Sugar & $\mathrm{A}$ & 99.9 & 99.9 & - & - & - & - \\
Sucralose & $\mathrm{B}$ & 98.8 & 7.1 & - & - & - & - \\
Butter & $\mathrm{C}$ & 0.8 & $\mathrm{~N} / \mathrm{A}$ & 82 & 51.3 & 0.6 & N/A \\
Coconut oil & $\mathrm{D}$ & - & - & 100 & 93 & - & N/A \\
Whole milk & $\mathrm{C}$ & 4.5 & 4.5 & 3.3 & 2.1 & 3.0 & N/A \\
Light milk & $\mathrm{C}$ & 5.0 & 5.0 & 0.1 & - & 3.1 & N/A \\
Lactose-free milk & $\mathrm{C}$ & 4.7 & 4.7 & 1.5 & 0.9 & 3.0 & N/A \\
Coconut milk & $\mathrm{E}$ & 2.7 & 1.9 & 0.9 & 0.9 & 0.1 & 0.1 \\
Soy milk & $\mathrm{E}$ & 2.5 & 2.5 & 1.8 & 0.3 & 3.0 & 0.5 \\
\hline
\end{tabular}

SFA: Saturated fatty acids, N/A: Not available 


\section{Statistical Analysis}

All data were analyzed using SPSS 22.0 statistical package program. Arithmetic mean and standard deviation values $(\overline{\mathrm{x}}$ \pm SD) are given as descriptive statistics for variables. KruskalWallis test was to determine differences among TAS, TOS and OSI values of different coffee samples. Moreover, pairwise comparisons of OSI values among coffee types were shown with Mann-Whitney U test. Statistically significance level was accepted as $\mathrm{p}<0.05$ for all analyses.

\section{Results and Discussion}

Coffee is one the most consumed beverages on a global scale due to its flavor and certain potential effects (Wang \& Ho, 2009). Many people add some ingredients to coffee instead of consuming it plain in order to obtain a smooth taste or to increase its flavor and health contributions (Al-Ghafari et al., 2017). However, information about the effects of the added ingredients on coffee, which is known for its polyphenol and antioxidant capacity, is limited, and research in this regard still continues. On this context, the study was conducted in order to investigate the effects of adding ingredients with very different chemical properties and matrices on their own and/or in combination on the antioxidant/oxidant status of coffee in a wide range.

Table 2. Temperature $\left({ }^{\circ} \mathrm{C}\right)$, dry matter content $\left(\operatorname{Brix}^{0}\right)$, TAS $(\mathrm{mmol} / \mathrm{L})$, TOS $(\mu \mathrm{mol} / \mathrm{L})$ and OSI values of roasted coffee with added ingredients brewed with filter coffee machine

\begin{tabular}{|c|c|c|c|c|c|}
\hline Ingredients and quantity & $\begin{array}{c}\text { Temperature } \\
\left({ }^{\circ} \mathrm{C}\right)\end{array}$ & $\begin{array}{c}\text { Dry matter } \\
\left(\text { Brix }^{0}\right)\end{array}$ & $\begin{array}{c}\text { TAS } \\
(\mathrm{mmol} / \mathrm{L})\end{array}$ & $\begin{array}{c}\text { TOS } \\
(\mu \mathrm{mol} / \mathrm{L})\end{array}$ & OSI \\
\hline Black (just brewed coffee) & 61.8 & 1.336 & $2.97 \pm 0.00$ & $49.11 \pm 7.29$ & $1.65 \pm 0.25$ \\
\hline \multicolumn{6}{|l|}{ Sweeteners } \\
\hline Sugar $(5 \mathrm{~g})$ & 46.8 & 1.349 & $2.98 \pm 0.01$ & $59.97 \pm 2.42$ & $2.02 \pm 0.08$ \\
\hline Sucralose $(0.5 \mathrm{~g})$ & 48.2 & 1.336 & $2.97 \pm 0.01$ & $52.38 \pm 1.01$ & $1.77 \pm 0.03$ \\
\hline \multicolumn{6}{|l|}{ Fats and Oils } \\
\hline Butter (5 g) & 42.7 & 1.336 & $2.98 \pm 0.00$ & $48.33 \pm 6.16$ & $1.62 \pm 0.21$ \\
\hline Coconut oil $(5 \mathrm{~g})$ & 41.1 & N/A & $2.96 \pm 0.01$ & $55.54 \pm 1.50$ & $1.87 \pm 0.05$ \\
\hline \multicolumn{6}{|l|}{ Milks } \\
\hline Whole milk $(30 \mathrm{~mL})$ & 42.9 & 1.342 & $3.12 \pm 0.04$ & $36.32 \pm 3.69$ & $1.16 \pm 0.10$ \\
\hline Light milk (30 mL) & 39.1 & 1.338 & $3.03 \pm 0.01$ & $34.96 \pm 3.93$ & $1.16 \pm 0.13$ \\
\hline Lactose free milk $(30 \mathrm{~mL})$ & 42.8 & 1.340 & $3.04 \pm 0.00$ & $30.24 \pm 1.09$ & $0.99 \pm 0.04$ \\
\hline Coconut milk $(30 \mathrm{~mL})$ & 39.5 & 1.337 & $3.00 \pm 0.01$ & $42.99 \pm 4.59$ & $1.43 \pm 0.15$ \\
\hline Soy milk $(30 \mathrm{~mL})$ & 40.8 & 1.338 & $2.92 \pm 0.01$ & $6.58 \pm 0.27$ & $0.23 \pm 0.01$ \\
\hline \multicolumn{6}{|l|}{ Milk with sweeteners } \\
\hline Whole milk $(30 \mathrm{~mL})$ with sugar $(5 \mathrm{~g})$ & 39.4 & 1.353 & $3.16 \pm 0.01$ & $38.48 \pm 0.31$ & $1.22 \pm 0.01$ \\
\hline Light milk (30 mL) with sugar (5 g) & 41.4 & 1.353 & $3.04 \pm 0.02$ & $36.14 \pm 3.41$ & $1.19 \pm 0.12$ \\
\hline Lactose free milk $(30 \mathrm{~mL})$ with sugar $(5 \mathrm{~g})$ & 40.3 & 1.350 & $3.04 \pm 0.00$ & $36.51 \pm 2.62$ & $1.20 \pm 0.09$ \\
\hline Coconut milk $(30 \mathrm{~mL})$ with sugar $(5 \mathrm{~g})$ & 39.8 & 1.347 & $3.02 \pm 0.02$ & $46.54 \pm 3.36$ & $1.54 \pm 0.10$ \\
\hline Soy milk $(30 \mathrm{~mL})$ with sugar $(5 \mathrm{~g})$ & 39.3 & 1.347 & $2.92 \pm 0.01$ & $6.41 \pm 0.61$ & $0.22 \pm 0.02$ \\
\hline Whole milk $(30 \mathrm{~mL})$ with sucralose $(0.5 \mathrm{~g})$ & 41.1 & 1.341 & $3.09 \pm 0.06$ & $33.80 \pm 1.59$ & $1.09 \pm 0.03$ \\
\hline Light milk $(30 \mathrm{~mL})$ with sucralose $(0.5 \mathrm{~g})$ & 41.1 & 1.339 & $3.04 \pm 0.02$ & $36.78 \pm 2.70$ & $1.21 \pm 0.10$ \\
\hline Lactose free milk $(30 \mathrm{~mL})$ with sucralose $(0.5 \mathrm{~g})$ & 42.8 & 1.340 & $3.04 \pm 0.00$ & $34.92 \pm 0.01$ & $1.15 \pm 0.00$ \\
\hline Coconut milk $(30 \mathrm{~mL})$ with sucralose $(0.5 \mathrm{~g})$ & 43.5 & 1.336 & $3.02 \pm 0.03$ & $39.56 \pm 0.79$ & $1.31 \pm 0.01$ \\
\hline Soy milk $(30 \mathrm{~mL})$ with sucralose $(0.5 \mathrm{~g})$ & 40.5 & 1.339 & $2.88 \pm 0.00$ & $4.62 \pm 0.59$ & $0.16 \pm 0.02$ \\
\hline p value* & & & $p=0.000$ & $p=0.000$ & $p=0.000$ \\
\hline
\end{tabular}

Dry matter: Water soluble dry matter content, TAS: Total antioxidant status, TOS: Total oxidant status, OSI: Oxidative stress index, N/A: Not available

*Kruskal Wallis test 
In the present study, TAS value of plain/black Brazilian mild roasted coffee brewed with filter coffee machine was determined to be $2.97 \pm 0.00 \mathrm{mmol} / \mathrm{L}$ (Table 2). Before it is roasted, the green coffee bean has a complex matrix of carbohydrate ( $\sim 60 \%$ in dry substance), lipid $(8 \%-18 \%$ in dry substance), protein, peptide and free amino acid $(9 \%-16 \%$ in dry substance), caffeine and trigonelline, theobromine, theophylline. It is reported that coffee bean contains $6-10 \%$ polyphenol in dry substance, that the most dominant of these polyphenols are chlorogenic acids (CGAs) - including the caffeoylquinic acids (CQAs), especially 5-CQA, and that it contains feruloylquinic acids and dicaffeoylquinic acids in less amounts (Acar-Tek, Ağagündüz, \& Ayhan, 2018). It has also been reported that coffee polyphenols, especially chlorogenic acid, have health improving anti-inflammatory, anticarcinogenic, antidiabetic, and antihypertension effects. Besides, there is evidence that chlorogenic acid protects vascular endothelial cells and reduces metabolic syndrome risk by increasing endothelial nitric oxide synthase expression and nitric oxide generation with its antioxidant properties (Yamagata, 2018). Although partial reductions and/or transformations may occur in these components following the roasting of coffee beans $\left(180-250^{\circ} \mathrm{C}\right)$, coffee continues to show its antioxidant activity (Acar-Tek et al., 2018; Richelle, Tavazzi, \& Offord, 2001) In a study in which the effects of the production and roasting conditions of coffee on the antioxidant effects of coffee brews were investigated, it was reported that especially light and medium roasted coffee brews had the highest antioxidant activity compared to dark coffee, and that they might protect cells from oxidative stress damages (Duarte, Abreu, Menezes, Santos, \& Gouvêa, 2005). Similarly, as it was aimed to examine the antioxidant activities of coffee brews in this study, medium roasting method was employed. Furthermore, when antioxidant activity and bioactive substances are handled, extraction mechanisms in obtaining coffee brews play an important role as well (Caprioli, Cortese, Sagratini, \& Vittori, 2015). Filtering method is one of the leading extraction techniques in terms of the antioxidant activity of coffee. In a study that supports this, the antioxidant capacities of the aqueous spent coffee extracts were determined as 46.0$102.3 \%$ (filter), $59.2-85.6 \%$ (espresso), and $<42 \%$ (plunger) (Bravo et al., 2012). The results of this study reflect the results of brewing method using filter coffee machine.

One of the most significant findings of this study was that the added milk types could change the antioxidant/oxidant capacity of coffee in different ways depending on the fractions and sources/types of milk (Table 2, Figure 1). In the study, it was determined that the antioxidant activities of the coffee types (with/without sucralose) to which various cow milk fractions (whole, light, lactose-free), especially whole cow milk (20\%), were added were significantly higher compared to other coffee types, including black coffee (Table 2). Among the ingredients that can be added to coffee, especially milk is one of the leading ingredients due to its nutritional composition (protein, fat, sugars and vitamins-minerals). Milk is a food product that contains many essential nutrients as well as many components with antioxidant effects. Protein fractions in milk, especially casein, show antioxidant activity (Fardet $\&$ Rock, 2018). Antioxidant enzymes in milk, such as superoxide dismutase (SOD), catalase (CAT) and glutathione peroxidase (GSH-Px) and conjugated linoleic acid, coenzyme Q10, vitamins C, E, A and D3, equol, uric acid, carotenoids, and minerals contribute to the antioxidant activity of milk (Fardet \& Rock, 2018; Khan et al., 2019). However, when milk is added to coffee, milk proteins such as whey and casein interact with coffee polyphenols by forming a complex. This condition may have an effect on functional and nutritional properties of coffee (Al-Ghafari et al., 2017). Similar to this study, in a study, it was determined that milk added to coffee by $10 \%$ and $20 \%$ enhanced the scavenging of 2,2-diphenyl1-pycrylhydrazyl (DPPH) or decreased the metal chelating and metal reducing activity of polyphenol (Al-Ghafari et al., 2017). In contrast to this study, it was determined that adding milk to instant coffee brews decreased the total phenol and chlorogenic acid variety components, and ABTS and ferricreducing antioxidant power (FRAP) antioxidant activities (Niseteo et al., 2012). Even in a study, addition of fresh whole milk or evaporated milk affected antioxidant activity through different mechanisms due to solid substance ingredients (fat and protein) (Alsufiani, 2017). In another study conducted, it was determined that when milk was added to coffee by $25 \%$, approximately $40 \%$ of chlorogenic acid in coffee was in a bonded condition and its bioavailability decreased, but that addition of milk did not have a significant effect on coffee's DPPH and 2-2'-azobis (2-amidinopropane) dihydrochloride (AAPH)-antioxidant effect (Dupas et al., 2006). As issues such as the type of coffee and the amount of added milk mostly are not clearly stated, and a standard evaluation method is not used, it becomes difficult to evaluate the studies. Also, the studies conducted in the literature mostly focused on how the milk added to coffee changed the bioavailability of coffee (Duarte \& Farah, 2011; Quan et al., 2020; Renouf et al., 2010). In a study conducted, it was reported that addition of whole milk did not change the overall bioavailability of coffee polyphenols, but that sugar and non-dairy creamer affected the maximum plasma concentration- $\mathrm{C}$ (max) of coffee polyphenols and the time needed to reach $\mathrm{C}(\max )-$ $\mathrm{T}(\max )$ (Renouf et al., 2010). In another study, consumption of coffee and milk together was determined to decrease the bioavailability of chlorogenic acid and metabolites (40\% vs $68 \%$ ) compared to consuming coffee plain (Duarte \& Farah, 2011). In yet another study, the effect of addition of milk in 
different matrices (skimmed milk and whole milk) on antioxidant capacity in in vitro gastrointestinal digestion model and the bio-accessibility of phenolics was investigated, and following the additions of milk, the antioxidant capacity of all samples were reduced or did not change. However, it was determined that especially the addition of whole milk displayed better phenolic bio-accessibility compared to skimmed milk (Quan et al., 2020). These results shed light on the necessity in future studies for a focus not only on nutritional matrix and capacity changes, but also on how it changes bioavailability and antioxidant capacity in different models.

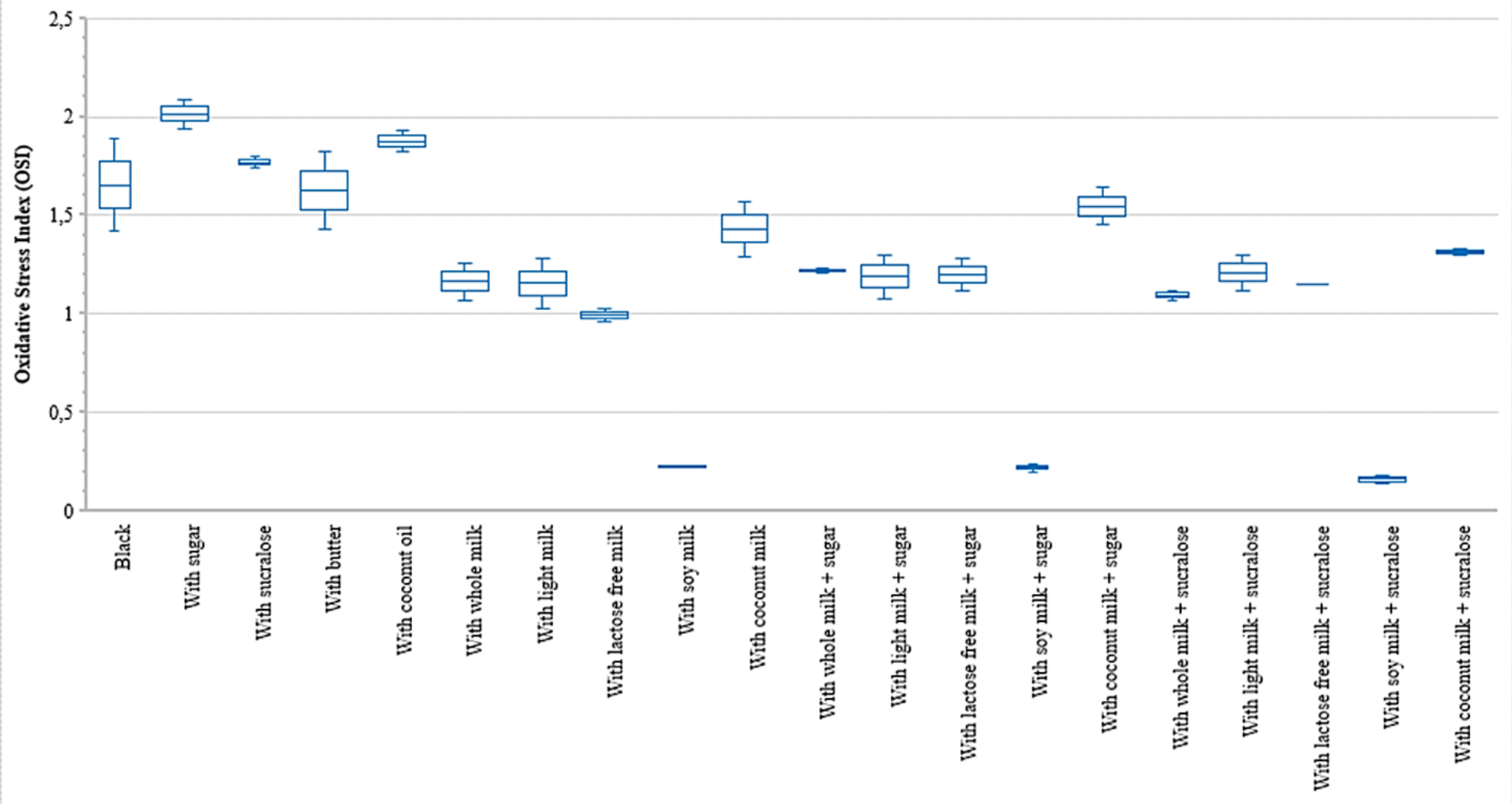

Coffee Group

Figure 1. The OSI values of coffee samples with different ingredients. Pairwise comparisons of coffee groups according to OSI (Mann Whitney U test, $p<0.05$ ): 1) OSI of the coffee "with whole milk" was statistically lower than OSI of the "black coffee", "coffee with sugar", "with sucralose", "with butter" and "with coconut oil". 2) OSI of the coffee "with light milk" was statistically lower than OSI of the "coffee with sugar" and "with coconut oil". 3) OSI of the coffee "with lactose-free milk" was statistically lower than OSI of the "black coffee", "coffee with sugar", "with sucralose", "with butter", "with coconut oil", "with coconut milk" and with coconut milk+sugar". 4) OSI of the coffee "with soy milk", "with soy milk+sugar" and "with soy milk+sucralose" were statistically lower than OSI of the "black coffee", "coffee with sugar", "with sucralose", "with butter", "with coconut oil", "with coconut milk", with coconut milk+sugar" and "with coconut milk+sucralose

Reactive oxygen species (ROS) are formed during cellular metabolism of macronutrient elements in energy production. As they are highly reactive molecules, lipids cause damage to biological structures such as proteins, polysaccharides, and DNA. Under normal physiological conditions, antioxidants can block the harmful effects of ROS, but in case of an imbalance between ROS and antioxidant defense mechanisms, oxidative stress can occur (Kalyanaraman, 2013). One of the important findings of this study was that the added ingredients could change oxidant activity/oxidative stress rather than antioxidant activity (Table 2, Figure 1). TOS value and OSI value of plain/black roasted coffee brewed with filter coffee machines was found to be $49.11 \pm 7.29 \mu \mathrm{mol} / \mathrm{L}$ and 1.65 \pm 0.25 , respectively, and especially addition of soy milk from plant-based milk types (sucralose and sugar combinations included) decreased these values significantly. Soybean and soy products have a matrix composed of bioactive components such as saponins, protease inhibitors, phytic acid and isoflavones (Barrett, 2006). Soy bean stands out with its high 
isoflavones content (McCue, Horii, \& Shetty, 2004). Isoflavones, also known as phytoestrogens, are compounds with estrogen-like structures (Barrett, 2006). Polyphenols are mostly found in the form of glucosides (daidzin and genistin) and aglycones (daidzein and genistein), and the antioxidant activity of soy bonds with these compounds (McCue et al., 2004). In a similar study to the present study, the antioxidant capability of UHT soy milk was found to be higher compared to normal UHT milk, and it was claimed that these antioxidant properties could not be explained only by phenolic compounds, and that peptides and amino-acids in soy milk resulting from the UHT production process could also display antioxidant properties (Baghbadorani et al., 2017). In another study conducted, it was reported that adding soy milk to tea types increased and/or did not change total antioxidant activity, but that it could be a better alternative in terms of antioxidant activity compared to bovine milk (Ryan \& Sutherland, 2011). It was reported that when green coffee extract was enhanced with soy milk $(0.025-1 \mathrm{mg})$, phenolic substance content increased up to $70 \%$, and that the antiradical activity and reducing power increased by 2 to 10 times (Sęczyk, Świeca, \& Gawlik-Dziki, 2017). In another study carried out, consumption of probiotic soymilk with the dosage of $200 \mathrm{~mL}$ per day by Type 2 diabetic kidney patients improved their oxidative stress markers (Miraghajani, Zaghian, Mirlohi, Feizi, \& Ghiasvand, 2017). As reported in other studies as well, it is thought that the antioxidant content and activity of soy is the main reason for the positive effect of soymilk on oxidative stress in this study.

In the present study, another finding was that the oxidant status and oxidative stress of coffee samples added with sugar and sucralose (single or in combination) were found to be higher in comparison to coffee samples with no addition (Table 2, Figure 1). In a similar study conducted on Turkish-style coffee brews, it was determined that light roasted coffee had higher polyphenol content, but that medium roasted coffee brews showed higher antioxidant capacity, and that especially those without sugar provided more health benefits (Nakilcioğlu-Taş, 2018). On the other hand, in another study, addition of sugar, milk, and lemon juice to green tea was determined not to change the antioxidant capacity of tea infusions significantly (Bartoszek, Polak, \& Chorążewski, 2018). Again, in a study on black tea, it was observed that radical scavenging activity of black tea was the highest, followed by black tea + sugar and black tea + milk+sugar (Sharma, Vijay Kumar, \& Jagan Mohan Rao, 2008). Even in a study, it was determined that alternative sweeteners to refined sugar such as dark and blackstrap molasses (FRAP: 4.6 to 4.9 mmol/100g), maple syrup, brown sugar, and honey (FRAP: 0.2 to $0.7 \mathrm{mmol} / 100 \mathrm{~g}$ ) had higher antioxidant activities (Phillips, Carlsen, \& Blomhoff, 2009). In this study too, it was determined that the use of sucralose, which is a non-nutritive, zero-calorie artificial sweetener, instead of sugar could be a better alternative in terms of oxidative status and stress (Table 2, Figure 1). Sucralose, 600 times sweeter than sugar, is a chlorinated (three chlorine atoms replace three hydroxyl groups) sugar substitute approved by the U.S. Food and Drug Administration (AlDeeb, Mahgoub, \& Foda, 2013). Although there is an accumulated literature regarding the use of artificial sweeteners like sucralose in the struggle against obesity (Khan, 2015), there is almost no information on its potential antioxidant/oxidative effects. Though the health effects of these sweeteners are still being discussed, it was found in this study that they had more promising effects in terms of oxidative status in comparison to common table sugar. This situation can be associated with the fact that consumers put less amounts of sucralose than common table sugar equivalent to the taste of sugar in order to consume their coffee for sensorial reasons.

In this study, the oxidant status and oxidative stress of especially coffee samples with coconut oil addition (single or in combination) were found to be higher (Table 2, Figure 1). Coconut oil is an edible oil that is extracted from the kernel of mature coconuts harvested from the coconut palm. Coconut oil has an increasing popularity recently due to its bioactive substance and particularly medium-chain fatty acids content (Wallace, 2019). However, there are contradictory findings regarding its effects on health and nutrition, especially on blood lipids (Boateng, Ansong, Owusu, \& Steiner-Asiedu, 2016). In the literature, it is stated that coconut oil intake should not exceed $10 \%$ of total caloric intake, especially due to its saturated fatty acid content and cardiometabolic profile. It was also determined in the same study that its addition to coffee samples was not a good strategy in terms of oxidative status (Santos, Howell, Earnest, \& Teixeira, 2019). For those who are fond of its flavor, coconut milk consumption could be a better choice instead of consuming oil fraction.

\section{Conclusion}

In conclusion, in this study, in which the effect of ingredients with different chemical structure and nutritional matrix on the antioxidant and oxidant status of brewed coffee was investigated and it was determined that mostly the oxidant status/oxidative stress of coffee rather than its antioxidant capacity could change depending on the added ingredients.

There are some limitations in this study. The first of these limitations is that characterization of nutrients and bioactive substances which may affect the antioxidant/oxidant capacity of coffee samples was not conducted in this study. Secondly, all antioxidant/oxidant capacity values of coffee samples added ingredients found in this study could not be compared 
since there was not any similar study related to some ingredients in the literature. Thirdly, this study only reflects the results of the filtered- Brazilian mild roasted coffee. Therefore, it is thought that the results obtained in this study may be partially limited in the generalization of the all coffee types using different beans, extraction and preparation methods. It is recommended to consider these conditions in future studies.

\section{Compliance with Ethical Standard}

Conflict of interests: The author declares that for this article they have no actual, potential or perceived conflict of interests.

Ethics committee approval: Author declare that this study does not include any experiments with human or animal subjects.

Funding disclosure: -

Acknowledgments: -

Disclosure: -

\section{References}

Acar-Tek, N., Ağagündüz, D., Ayhan, B. (2018). Effect of green coffee consumption on resting energy expenditure, blood pressure, and body temperature in healthy women: A pilot study. Journal of the American College of Nutrition, 37(8), 691-700.

https://doi.org/10.1080/07315724.2018.1461147

Agudelo-Ochoa, G.M., Pulgarín-Zapata, I. C., VelásquezRodriguez, C. M., Duque-Ramírez, M., Naranjo-Cano, M., Quintero-Ortiz, M. M., . . Munoz-Durango, K. (2016). Coffee consumption increases the antioxidant capacity of plasma and has no effect on the lipid profile or vascular function in healthy adults in a randomized controlled trial. The Journal of nutrition, 146(3), 524-531.

https://doi.org/10.3945/jn.115.224774

Al-Ghafari, A.B., Alharbi, R.H., Al-Jehani, M.M., Bujeir, S.A., Al Doghaither, H.A., Omar, U. M. (2017). The Effect of Adding Different Concentrations of Cows' Milk on the Antioxidant Properties of Coffee. Biosciences Biotechnology Research Asia, 14(1), 177-184.

https://doi.org/10.13005/bbra/2433

AlDeeb, O.A., Mahgoub, H., Foda, N.H. (2013). Sucralose. In Profiles of Drug Substances, Excipients and Related Methodology (Vol. 38, pp. 423-462): Elsevier.

Alongi, M., Calligaris, S., Anese, M. (2019). Fat concentration and high-pressure homogenization affect chlorogenic acid bioaccessibility and $\alpha$-glucosidase inhibitory capacity of milk-based coffee beverages. Journal of Functional Foods, 58, 130-137.

https://doi.org/10.1016/j.jff.2019.04.057

Baghbadorani, S.T., Ehsani, M.R., Mirlohi, M., Ezzatpanah, H., Azadbakht, L., Babashahi, M. (2017). Antioxidant capability of ultra-high temperature milk and ultra-high temperature soy milk and their fermented products determined by four distinct spectrophotometric methods. Advanced Biomedical Research, 6.

https://doi.org/10.4103/2277-9175.207150

Barrett, J.R. (2006). The science of soy: what do we really know? In: National Institute of Environmental Health Sciences.

https://doi.org/10.1289/ehp.114-a352

Bartoszek, M., Polak, J., Chorążewski, M. (2018). Comparison of antioxidant capacities of different types of tea using the spectroscopy methods and semi-empirical mathematical model. European Food Research and Technology, 244(4), 595-601.

https://oi.org/10.1007/s00217-017-2986-Z

Boateng, L., Ansong, R., Owusu, W., Steiner-Asiedu, M. (2016). Coconut oil and palm oil's role in nutrition, health and national development: A review. Ghana medical journal, 50(3), 189-196.

http://dx.doi.org/10.4314/gmj.v50i3.11

Bravo, J., Juaniz, I., Monente, C., Caemmerer, B., Kroh, L.W., De Peña, M. P., Cid, C. (2012). Evaluation of spent coffee obtained from the most common coffeemakers as a source of hydrophilic bioactive compounds. Journal of Agricultural and Food Chemistry, 60(51), 12565-12573.

https://doi.org/10.1021/jf3040594

Caprioli, G., Cortese, M., Sagratini, G., Vittori, S. (2015). The influence of different types of preparation (espresso and brew) on coffee aroma and main bioactive constituents. International Journal of Food Sciences and Nutrition, 66(5), 505-513. https://doi.org/10.3109/09637486.2015.1064871

del Castillo, M.D., Ames, J.M., Gordon, M.H. (2002). Effect of roasting on the antioxidant activity of coffee brews. Journal of Agricultural and Food Chemistry, 50(13), 36983703.

https://doi.org/10.1590/S0101-20612005000200035 
Duarte, G.S., Farah, A. (2011).

Effect of simultaneous consumption of milk and coffee on chlorogenic acids' bioavailability in humans. Journal of Agricultural and Food Chemistry, 59(14), 7925-7931. https://doi.org/10.1021/jf201906p

Duarte, S.M.d.S., Abreu, C.M.P.d., Menezes, H.C.d., Santos, M.H.d., Gouvêa, C.M.C.P. (2005). Effect of processing and roasting on the antioxidant activity of coffee brews. Food Science and Technology, 25(2), 387-393. https://doi.org/10.1590/S0101-20612005000200035

Dupas, C.J., Marsset-Baglieri, A.C., Ordonaud, C.S., Ducept, F.M., Maillard, M.N. (2006). Coffee antioxidant properties: effects of milk addition and processing conditions. Journal of food science, 71(3), S253-S258.

https://doi.org/10.1111/j.1365-2621.2006.tb15650.x

Erel, O. (2004). A novel automated direct measurement method for total antioxidant capacity using a new generation, more stable ABTS radical cation. Clinical biochemistry, 37(4), 277-285.

https://doi.org/10.1016/j.clinbiochem.2003.11.015

Erel, O. (2005). A new automated colorimetric method for measuring total oxidant status. Clin Biochem, 38(12), 11031111.

https://doi.org/10.1016/j.clinbiochem.2005.08.008

Fardet, A., Rock, E. (2018). In vitro and in vivo antioxidant potential of milks, yoghurts, fermented milks and cheeses: a narrative review of evidence. Nutrition research reviews, 31(1), 52-70.

https://doi.org/10.1017/S0954422417000191

Gómez-Ruiz, J.Á., Leake, D.S., Ames, J.M. (2007). In vitro antioxidant activity of coffee compounds and their metabolites. Journal of Agricultural and Food Chemistry, 55(17), 6962-6969.

https://doi.org/10.1021/jf0710985

Hadeil, M., Alsufiani, U.M.O. (2017). A Comparative Study to Evaluate the Polyphenol Content and Antioxidant Activity of Coffee with Fresh Whole Milk and Evaporated Milk Food and Public Health, 7(4), 75-80.

https://doi.org/ 10.5923/j.fph.20170704.01

Hu, G.L., Wang, X., Zhang, L., Qiu, M.H. (2019). The sources and mechanisms of bioactive ingredients in coffee. Food Funct, 10(6), 3113-3126.

https://doi.org/ 10.1039/C9FO00288J
Kalyanaraman, B. (2013). Teaching the basics of redox biology to medical and graduate students: oxidants, antioxidants and disease mechanisms. Redox biology, 1(1), 244-257.

https://doi.org/10.1016/j.redox.2013.01.014

Khan, I. T., Nadeem, M., Imran, M., Ullah, R., Ajmal, M., Jaspal, M.H. (2019). Antioxidant properties of Milk and dairy products: a comprehensive review of the current knowledge. Lipids in health and disease, 18(1), 41.

https://doi.org/10.1186/s12944-019-0969-8

Khan, S.A. (2015). Artificial sweeteners: safe or unsafe? JPMA. The Journal of the Pakistan Medical Association, 65(2), 225-227.

Martini, D., Del Bo, C., Tassotti, M., Riso, P., Del Rio, D., Brighenti, F., Porrini, M. (2016). Coffee consumption and oxidative stress: a review of human intervention studies. Molecules, 21(8), 979.

https://doi.org/10.3390/molecules21080979

McCue, P., Horii, A., Shetty, K. (2004). Mobilization of phenolic antioxidants from defatted soybean powders by Lentinus edodes during solid-state bioprocessing is associated with enhanced production of laccase. Innovative Food Science \& Emerging Technologies, 5(3), 385-392.

https://doi.org/10.1016/j.ifset.2004.05.003

Miraghajani, M., Zaghian, N., Mirlohi, M., Feizi, A., Ghiasvand, R. (2017). The impact of probiotic soy milk consumption on oxidative stress among type 2 diabetic kidney disease patients: a randomized controlled clinical trial. Journal of Renal Nutrition, 27(5), 317-324.

https://doi.org/10.1053/j.jrn.2017.04.004

Nakilcioğlu-Taş, E. (2018). The Effects of Sugar Addition and Degree of Roast on the Bioactive Compounds and Antioxidant Activity of Turkish-Style Coffee Brews. Indian Journal of Pharmaceutical Education and Research, 52(3), 456-466.

https://doi.org/10.5530/ijper.52.3.53

Niseteo, T., Komes, D., Belščak-Cvitanović, A., Horžić, D., Budeč, M. (2012). Bioactive composition and antioxidant potential of different commonly consumed coffee brews affected by their preparation technique and milk addition. Food Chemistry, 134(4), 1870-1877.

https://doi.org/ 10.1016/j.foodchem.2012.03.095 
Phillips, K.M., Carlsen, M.H., Blomhoff, R. (2009). Total antioxidant content of alternatives to refined sugar. Journal of the American Dietetic Association, 109(1), 64-71.

https://doi.org/10.1016/j.jada.2008.10.014

Poole, R., Kennedy, O.J., Roderick, P., Fallowfield, J.A., Hayes, P.C., Parkes, J. (2017). Coffee consumption and health: umbrella review of meta-analyses of multiple health outcomes. BMJ, 359, j5024.

https://doi.org/ 10.1136/bmj.j5024

Quan, W., Qie, X., Chen, Y., Zeng, M., Qin, F., Chen, J., He, Z. (2020). Effect of milk addition and processing on the antioxidant capacity and phenolic bioaccessibility of coffee by using an in vitro gastrointestinal digestion model. Food Chemistry, 308, 125598.

https://doi.org/ 10.1016/j.foodchem.2019.125598

Renouf, M., Marmet, C., Guy, P., Fraering, A.-L., Longet, K., Moulin, J., . . . Dionisi, F. (2010). Nondairy creamer, but not milk, delays the appearance of coffee phenolic acid equivalents in human plasma. The Journal of nutrition, 140(2), 259-263.

https://doi.org/10.3945/jn.109.113027

Richelle, M., Tavazzi, I., Offord, E. (2001). Comparison of the antioxidant activity of commonly consumed polyphenolic beverages (coffee, cocoa, and tea) prepared per cup serving. Journal of Agricultural and Food Chemistry, 49(7), 34383442.

https://doi.org/10.1021/jf0101410

Ryan, L., Sutherland, S. (2011). Comparison of the effects of different types of soya milk on the total antioxidant capacity of black tea infusions. Food Research International, 44(9), 3115-3117.

https://doi.org/10.1016/j.foodres.2011.06.003

Samoggia, A., \& Riedel, B. (2019). Consumers' Perceptions of Coffee Health Benefits and Motives for Coffee Consumption and Purchasing. Nutrients, 11(3).

https://doi.org/ 10.3390/nu11030653

Santos, H.O., Howell, S., Earnest, C.P., Teixeira, F. J. (2019). Coconut oil intake and its effects on the cardiometabolic profile-A structured literature review. Progress in cardiovascular diseases, 62(5), 436-443.

https://doi.org/10.1016/j.pcad.2019.11.001

Sęczyk, Ł., Świeca, M., Gawlik-Dziki, U. (2017). Soymilk enriched with green coffee phenolics-Antioxidant and nutritional properties in the light of phenolics-food matrix interactions. Food Chemistry, 223, 1-7.

https://doi.org/ 10.1016/j.foodchem.2016.12.020

Shaposhnikov, S., Hatzold, T., EI Yamani, N., Stavro, P. M., Lorenzo, Y., Dusinska, M., . . . Collins, A. (2018). Coffee and oxidative stress: a human intervention study. European Journal of Nutrition, 57(2), 533-544.

https://doi.org/ 10.1007/s00394-016-1336-4

Sharma, V., Vijay Kumar, H., Jagan Mohan Rao, L. (2008). Influence of milk and sugar on antioxidant potential of black tea. Food Research International, 41(2), 124-129.

https://doi.org/ 10.1016/j.foodres.2007.10.009

The Specialty Coffee Association. Coffee standarts. (2020). Retrieved from https://sca.coffee/research/coffeestandards\#: : :text $=$ Brewing $\% 20$ Standards, Golden $\% 20 \mathrm{Cup} \%$ 20Standard\&text $=$ Coffee $\% 20$ shall $\% 20$ exhibit $\% 20 \mathrm{a} \% 20 \mathrm{bre}$ w,of $\% 2018 \% 20$ to $\% 2022 \% 20$ percent (accessed 20.03.2021).

Tajik, N., Tajik, M., Mack, I., Enck, P. (2017). The potential effects of chlorogenic acid, the main phenolic components in coffee, on health: a comprehensive review of the literature. European Journal of Nutrition, 56(7), 22152244.

https://doi.org/10.1007/s00394-017-1379-1

Tommy, H., Jennifer, M., Iris, M., Sit, W., Louie, J.C. (2020). Consuming decaffeinated coffee with milk and sugar added before a high glycaemic index meal improves postprandial glycaemic and insulinaemic responses in healthy adults. British Journal of Nutrition, 1-30. https://doi.org/ 10.1017/S0007114520001750

Wallace, T.C. (2019). Health effects of coconut oil-A narrative review of current evidence. Journal of the American College of Nutrition, 38(2), 97-107.

https://doi.org/ 10.1080/07315724.2018.1497562

Wang, Y., Ho, C.-T. (2009). Polyphenolic chemistry of tea and coffee: a century of progress. Journal of Agricultural and Food Chemistry, 57(18), 8109-8114.

https://doi.org/10.1021/jf804025c

Yamagata, K. (2018). Do coffee polyphenols have a preventive action on metabolic syndrome associated endothelial dysfunctions? An assessment of the current evidence. Antioxidants, 7(2), 26. https://doi.org/10.3390/antiox7020026 
Yanagimoto, K., Ochi, H., Lee, K.-G., Shibamoto, T. (2004). Antioxidative activities of fractions obtained from brewed coffee. Journal of Agricultural and Food Chemistry, 52(3), 592-596.

https://doi.org/ doi.org/10.1021/jf030317t
Yumru, M., Savas, H.A., Kalenderoglu, A., Bulut, M., Celik, H., Erel, O. (2009). Oxidative imbalance in bipolar disorder subtypes: a comparative study. Prog Neuropsychopharmacol Biol Psychiatry, 33(6), 1070-1074.

https://doi.org/10.1016/j.pnpbp.2009.06.005 